\title{
AN EMPIRICAL STUDY ON IMPACT OF USING GEOGEBRA ON ACHIEVEMENT IN MATHEMATICS
}

\author{
Dr. Pooja Pant \\ Assistant Professor, \\ Amity Institute of Education, \\ Amity University, \\ Uttar Pradesh,
}

Article DOI: https://doi.org/10.36713/epra6583

\begin{abstract}
This research paper is based on the study done by investigator to determine the impact of use of open educational resources on achievement of elementary level mathematics students. The study was experimental in nature. The data was collected from 120 students of elementary level of private schools in Delhi-NCR with ICT facilities. The objectives of the study were (a) To develop applets using Geogebra tool for teaching mathematics (b)To study the impact of using these applets on the achievement level students of mathematics. The results show that the impact of use of open educational resources on achievement of elementary level mathematics students is found to be significant at 0.01 level of significance.
\end{abstract}

KEY WORDS: Achievement, Elementary level students, Geogebra, Open Educational Resources

\section{INTRODUCTION}

Technology has provided a new dimension to the ever changing facet of education. With the paradigm shift in the role of the teachers the classroom scenario has also changed completely. In a class where there are learners with diverse needs the use of old chalk and talk method is strictly prohibited. Information and Communication Technology (ICT) is an exclusive tool which can be utilized in the field of education to address its various problems. In the present times with abundance of information available, we need teachers who are expert in using the technology in a judicious manner to optimize its utilization to its maximum extent. The $21^{\text {st }}$ century classrooms need to be driven by the ICT integrated teaching learning resources. We need to understand the clear difference between using ICT and teaching of ICT. Simply preparing a lesson based on ICT does not mean ICT competency of a teacher. Rather the teacher needs to identify suitable technological resources and successfully integrating them in the classroom. But technology comes with a cost so how the teachers are supposed to integrate these expensive technological tools into their teaching. For this purpose open educational resources need to be widely used by the teachers.

\section{Open Educational Resources}

Open Educational Resources (OERs) are any type of educational materials that are in the public domain or introduced with an open license. The nature of these open materials means that anyone can legally and freely copy, use, adapt and re-share them. OERs range from textbooks to curricula, syllabi, lecture notes, assignments, tests, projects, audio, video and animation.(UNESCO)

There are many commercial softwares available for teaching and learning Mathematics like Geometer's Sketchpad, Cabri, Matlab, etc. But teachers are unable to use them in the classroom as few of them are very expensive. However, there are softwares that could be freely used by educators in classroom teaching. The term Open Source Software (OSS) allows user to download any softwaresthat are available and suitable for the users. Softwares which are similar to OSS and related to mathematics instructions such as FreeMat, 
GeoNet, JLab, Maxima, Axiom, YACAS, JsMath and others are ready to be downloaded and used in teaching and learning

One such open Educational resource is Free Open Software GeoGebra. It is discussed below:

\section{GEOGEBRA}

GeoGebra is an open educational resource. It is a dynamic mathematics software tool that brings together geometry, algebra, spreadsheets, graphing, statistics and calculus and presents them as a package. It provides multiple representations of objects. Basically, the idea is to connect geometric, algebraic, and numeric representations in an interactive way. This can be accomplished with points, vectors, lines, and conic sections. This mathematics software in which there is a provision for entering as well as manipulating equations and coordinates, and hence plot functions; work with sliders to investigate parameters; find symbolic derivatives; and use commands such as Root or Sequence.

Key features include:

- Free to use software for learning, teaching of mathematics.

- Interactive with easy-to-use interface.

- Access to an ever-expanding pool of resources.

- Allows visual experience in mathematics

Hence, GeoGebra is a mathematical tool which covers many areas of mathematics.

Users all over the world can freely download this software from the official GeoGebra website at http://www.GeoGebra.org.

\section{Research Objectives}

The objectives of the study were

- To develop java applets using GeoGebra tool for teaching mathematics at elementary level
- To study the impact of using these applets on the achievement level students of mathematics at elementary level

\section{METHODOLOGY Sample}

The sample of the present study consisted of 120 children (60boys and 60girls) of class VIII from three schools in Delhi NCR. Purposive sampling technique was used for choosing the schools for the study based on the availability of ICT.

\section{Tools Used}

In the investigation following tools were used for data collection:

1. Monitoring performa, adopted by the investigator

2. Self- developed achievement test

\section{Statistical Technique}

Mean Score and ' $t$ ' test were used for analysis

The instructional material for this study consisted of lesson plans integrating GeoGebra for teaching two topics of mathematics of NCERT Class 8 for the experimental group and another set of plans in the convention group i.e. the control group. The Figure given below shows few snapshots taken by using GeoGebra software.

\section{FINDINGS}

The self-constructed Achievement questionnaire was administered on the 60 students each of control and experimental groups. The tool consisted of 25 questions of mathematics.

To examine the effect of use of GeoGebra on achievement of the respondents of control and experimental groups

We compare through pre and post- test the achievement of both control and experimental groups, which has been tabulated below.

Comparison of difference of mean of Pre and Post Achievement scores of both control and experimental group respondents

\begin{tabular}{|l|c|c|c|c|}
\hline Groups & $\mathbf{N}$ & Mean & SD & \multirow{2}{*}{ t-value } \\
\hline Control Group & 60 & 17.717 & 7.388 & \multirow{2}{*}{$12.852^{* *}$} \\
\cline { 1 - 4 } Experimental Group & 60 & 34.233 & 6.672 & \\
\hline
\end{tabular}

**Significant at 0.01 level

From the table given above it is evident that the comparisons of difference of mean of Pre and Post achievement scores of control and experimental groups on achievement test scores are 17.717 and 34.233 
respectively SD is 7.388 and 6.672 respectively. The $\mathrm{t}$ ratio is 12.852 , it signifies that the there is significant difference in the achievement score of both the control and the experimental groups after the experiment.

\section{CONCLUSION}

The results of the study indicated that there was a significant difference between the means of the students' achievement scores in mathematics. The findings showed that integration of GeoGebra for teaching acts as a booster in the traditional classroom of mathematics. Pedagogical innovations using GeoGebra is more effective than traditional pedagogical tools alone. The findings of this study are in line with the research results attained by Hennessy, Fung and Scanlon (2001), Hannafin and Foshay (2008), Ahmad Fauzi et. al. (2010) and Ahmad Tarmizi et. al. (2010) which depict that use of mathematical learning softwares has a positive effect on the students learning and understanding. It clearly demonstrates the instructional effectiveness of GeoGebra as compared to the traditional construction tools. This study gives an alternative to the teachers to utilize the free open mathematics software as a tool as an effective pedagogical tool. It is an cost effective free to us easy software.

\section{REFERENCES}

1. Ahmad Fauzi Ayub., Mohd Zin M., Wong Su Luan, \& Rohani Ahmad Tarmizi. (2010). A Comparison of Two Different Technologies Tools in Tutoring Calculus. Procedia - Social and Behavioral Sciences, 2(2), 481-486.

2. Hannafin, R. D., \& Foshay, W. R. (2008). Computer-based Instruction's (CBI) Rediscovered Role in K-12; An evaluation case study of one high school's use of CBI to improve pass rates on highstakes tests. Educational Technology Research \& Development, 56(2), 147-160.

3. Hennessy, S., Fung, P., \& Scanlon, E. (Writer) (2001). The Role of the Graphic Calculator in Mediating Graphing Activity [Article], International Journal of Mathematical Education in Science \& Technology: Taylor \& Francis Ltd.

4. Royati Abdul Saha et al. (2010). The Effects of GeoGebra on Mathematics Achievement:Enlightening Coordinate Geometry Learning .Procedia Social and Behavioral Sciences 8 (2010) 686-693

\section{WEBLINK}

http://www.unesco.org/new/en/communication-andinformation/access-to-knowledge/open-educationalresources/what-are-open-educational-resources-oers/ 